\title{
The Prevention of Cervical Cancer and Other HPV-Related Diseases of the Anogenital Region
}

Balla BC, M.D*

School of Ph.D. Studies, Semmelweis University, Hungary

Cervical cancer is the fourth most common cancer in women and the seventh most common cancer, with an estimated amount of 528,000 new cases worldwide in 2012 . The majority of cases occur in less developed regions where the estimated 2012 age-standardized incidence rate was more than $30 / 100,000$. These regions include eastern, southern and central Africa and Melanesia. The lowest incidence rates were registered in Australia, New Zealand and western Asia. Concerning mortality, about 266,000 deaths resulted from the malignancy in 2012, from which around $87 \%$ occurred in the less developed regions [1].

Cervical cancer is due to HPV infection [2], just like numerous other pathologies of the anogenital region e.g. genital warts, vulvar and vaginal cancer, anal cancer and penile cancer [3]. The virus is transmitted sexually, however transmission is also possible through non-penetrative sexual contact (for example hand to genitals) $[4,5]$ or vertically [6,7].

The estimated average lifetime probability of HPV infection is more than $80 \%$ for women and above $90 \%$ among men [8]. While HPV infection is mostly acquired in adolescence, two peaks of prevalence had been detected: the first one in the twenties and the second infection peak in middle-age (46-50), however the prevalence varies by virus types and region [9]. Studies have shown that $90 \%$ of infections of a particular type clear out within two years [10].

Based on their malignant potential, HPVs can be identified as highrisk and low-risk types. Low-risk HPV types include types 6,11, 42, 43 and 44 , while high-risk HPV types include types 16, 18, 31, 33, 34, 35, $39,45,51,52,56,58,59,66,68$ and 70 [11]. In case the infection of a high-risk HPV strain persists, progression to precancerous lesions may occur. HPV-16 and HPV-18 types are responsible for approximately $70 \%$ of cervical cancers, while HPV- 6 and HPV- 11 cause about $90 \%$ of genital warts [12].

Currently three prophylactic vaccines have been licensed and are recommended for immunization: the bivalent (types 16 and 18), the quadrivalent (types 6, 11, 16 and 18) and the 9-valent HPV vaccine (types $6,11,16,18,31,33,45,52$ and 58). Vaccination can be started at age 9 and continued through age 26, however it is recommended for routine vaccination at age 11 or 12 [13]. The vaccine can also be beneficial for men, especially for high-risk populations such as men who have sex with men (MSM) [14].

While the prophylactic vaccine may be an effective tool of reducing cervical cancer incidence, the regular attendance of cervical cancer screening (secondary prevention) remains a primordial element of diminishing incidence and mortality.

\section{References}

1. http://globocan.iarc.fr/Pages/fact_sheets_cancer.aspx (accessed Aug 11, 2016)

2. Walboomers JM, Jacobs MV, Manos MM, Bosch FX, Kummer JA, et al. (1999) Human papillomavirus is a necessary cause of invasive cervical cancer worldwide. J Pathol 189: 12-19.
3. Muñoz N, Castellsagué X, González AB, Gissmann L (2006) Chapter 1: HPV in the etiology of human cancer. Vaccine 24: 1-10.

4. Hernandez BY, Wilkens LR, Zhu X, Thompson P, McDuffie K, et al. (2008) Transmission of Human Papillomavirus in Heterosexual Couples. Emerg Infect Dis 14: 888-894.

5. Braaten KP, Laufer M R (2008) Human Papillomavirus (HPV), HPV-Related Disease, and the HPV Vaccine. Rev Obstet Gynecol 1: 2-10.

6. Larson DA, Derkay CS (2010) Epidemiology of recurrent respiratory papillomatosis. APMIS 118: 450-454.

7. Lee SM, Park JS, Norwitz ER, Koo JN, Oh IH, et al. (2013) Risk of Vertical Transmission of Human Papillomavirus throughout Pregnancy: A Prospective Study. PLoS ONE 8: e66368.

8. Chesson HW, Dunne EF, Hariri S, Markowitz LE (2014) The estimated lifetime probability of acquiring human papillomavirus in the United States. Sex Transm Dis 41: $660-664$

9. Smith JS, Melendy A, Rana RK, Pimenta JM (2008) Age-Specific Prevalence of Infection with Human Papillomavirus in Females: A Global Review. J Adolesc Health 43: 1-5.

10. Moscicki AB, Schiffman M, Kjaer S, Villa LL (2006) Chapter 5: Updating the natural history of HPV and anogenital cancer. Vaccine 24:42-51.

11. Burd EM (2003) Human Papillomavirus and Cervical Cancer. Clin Microbiol Rev 16: 1-17.

12. Clifford GM, Smith JS, Aguado T, Franceschi S (2003) Comparison of HPV type distribution in high-grade cervical lesions and cervical cancer: a meta-analysis. Br J Cancer 89: 101-105.

13. https://www.cdc.gov/vaccines/vpd/hpv/hcp/recommendations.htm (accessed Mar 24, 2017)

14. Kim JJ (2010) Targeted human papillomavirus vaccination of men who have sex with men in the USA: a cost-effectiveness modelling analysis. Lancet Infect Dis 10: 845-852.

*Corresponding author: Balla BC, M.D., School of Ph.D. Studies, Semmelweis University, Hungary, Tel: +3614591500/56184; E-mail: bettinaclaudia@icloud.com

Received March 25, 2017; Accepted March 27, 2017; Published March 30, 2017

Citation: Balla BC (2017) The Prevention of Cervical Cancer and Other HPVRelated Diseases of the Anogenital Region. J Health Med Informat 8: e104. doi 10.4172/2157-7420.1000e142

Copyright: (c) 2017 Balla BC. This is an open-access article distributed under the terms of the Creative Commons Attribution License, which permits unrestricted use, distribution, and reproduction in any medium, provided the original author and source are credited. 